\title{
AVALIAÇÃO DO POTENCIAL ALELOPÁTICO DE GENÓTIPOS DE AVEIA NO INÍCIO DO CICLO'
}

\author{
UBIRATÃ SOARES JACOB $\left.\right|^{2}$ e NILSON GILBERTO FLECK ${ }^{3}$
}

\begin{abstract}
RESUMO - A aveia (Avena spp.) é uma das culturas mais importantes do Sul do Brasil durante a estação hibernal de crescimento. Sabe-se que nela existem agentes alelopáticos, o que torna conveniente o entendimento deste fenômeno na cultura. Neste trabalho, buscou-se realizar uma estimativa do potencial alelopático com base na análise da fase inicial (estabelecimento) do ciclo de diferentes genótipos de aveia, bem como na avaliação de seus aleloquímicos. A partir da análise dos dados, verifica-se que os genótipos de aveia apresentam potencial alelopático, e que UPF 13, UFRGS 9, UFRGS 10 e UFRGS 6 são os que mostram maior efeito. Por outro lado, UFRGS 12, UFRGS 17, UFRGS 884077 e UPF 12 exibem menor efeito. Os efeitos produzidos pelo aleloquímico escopoletina são semelhantes aos provocados pelos próprios genótipos de aveia, o que mostra semelhança entre o efeito alelopático produzido pela substância e o provocado pelos genótipos.
\end{abstract}

Termos para indexação: Avena sativa, Avena strigosa, aleloquímicos, escopoletina, alelopatia.

\section{EVALUATION OF THE ALLELOPATHIC POTENTIAL OF OAT GENOTYPES AT THE INITIAL PERIOD OF CYCLE}

\begin{abstract}
Oats (Avena spp.) represent one of the most important crops in the South of Brazil during the winter growing season. In its plants there are allelopathic substances present, which refer the importance of the understanding of this phenomenon in the crop. The aim of this work was to estimate the allelopathic potential of different genotypes based on the analyses of their initial phase as well as on the evaluation of their allelochemicals. Results of this study showed that oat genotypes present allelopathic potential. Genotypes that present greater allelopathic effects during the initial period are UPF 13, UFRGS 9, UFRGS 10, and UFRGS 6 . In the same way, those genotypes that exhibit lesser effects are UFRGS 12, UFRGS 17, UFRGS 884077, and UPF 12 . The effects caused by the allelochemical scopoletin are similar to those observed by oat genotypes, suggesting a cause and effect relationship.

Index terms: Avena sativa, Avena strigosa, allelochemicals, scopoletin, allelopathy.
\end{abstract}

\section{INTRODUÇÃO}

A tentativa de obter plantas cultivadas com maior potencial alelopático para que possam competir com plantas infestantes baseia-se não apenas no resgate desta caraterística presente em tipos silvestres, mas também na seleção de cultivares que possam mostrar maior ou menor ação alelopática (Jacobi, 1997).

\footnotetext{
${ }^{1}$ Aceito para publicação em 19 de janeiro de 1998.

${ }^{2}$ Biólogo, Dr., Prof. Adjunto, Universidade de Ijuí, Caixa Postal 560, CEP 98700-000 Ijuí, RS. E-mail: bira@unijui.tche.br

${ }^{3}$ Eng. Agrôn., Ph.D., Fac. de Agronomia, UFRGS, Caixa Postal 776, CEP 90001-970 Porto Alegre, RS.
}

O primeiro trabalho nesta linha, utilizando aveia (Avena sp.), foi efetuado por Fay \& Duke (1977), que realizaram uma triagem procurando genótipos com maior potencial alelopático. Este estudo baseouse na exsudação de escopoletina pelas radículas de plântulas de aveia, substância conhecida como inibidora do crescimento vegetal, e levou à seleção de genótipos que mostravam maior capacidade de produção desse inibidor. Outros trabalhos, apresentando objetivos semelhantes, foram realizados com outras espécies (Putnam \& Duke, 1974; Leather, 1983; Rose et al., 1984; Alsaadawi, 1988; James et al., 1988; Dilday et al., 1992).

A escopoletina certamente não é o único composto alelopático presente na exsudação radicular de aveia, pois Perez \& Nunez (1991) identificaram, 
em exsudados de raízes de Avena fatua, além deste composto, cumarina, ácido p-hidroxibenzóico e ácido vanílico, o que indica que estes ou outros compostos possam também estar presentes em exsudados de raízes de Avena sativa ou em outras espécies de Avena.

Objetivou-se, neste trabalho, avaliar o potencial alelopático de diferentes genótipos de aveia, testar a ação fitotóxica da escopoletina, e ver se existe interação entre os efeitos do aleloquímico e os genótipos.

\section{MATERIAL E MÉTODOS}

As espécies e genótipos investigados foram aveia-branca (Avena sativa L.): cultivares UFRGS 4, UFRGS 6, UFRGS 7, UFRGS 8, UFRGS 9, UFRGS 10, UFRGS 11, UFRGS 12, UFRGS 15, UFRGS 17, UFRGS 18, UPF 5, UPF 7, UPF 12, UPF 13, UPF 14, UPF 15, CTC 2 e linhagem UFRGS 884077; aveia-preta (Avena strigosa). Estes genótipos foram testados sobre uma cultura da mesma época, trigo (Triticum aestivum L.), cultivar E-7414, e uma invasora da aveia, azevém (Lolium multiflorum Lam.). As sementes utilizadas foram esterilizadas com hipoclorito de sódio a 2\%. As placas de Petri, os vasos e os substratos foram autoclavados. À água utilizada nos experimentos foram acrescentados $20 \mathrm{mM}$ de sulfato de estreptomicina e $20 \mathrm{mM}$ de captan.

\section{Avaliação da exsudação de escopoletina pelas raízes}

As sementes foram colocadas para germinar sobre papel-filtro, formando rolos, com as sementes posicionadas a $5 \mathrm{~cm}$ da extremidade e com uma distância de $1 \mathrm{~cm}$ entre elas, e os rolos, em seguida, levados a uma câmara de crescimento com temperatura de $18^{\circ} \mathrm{C}$ e fotoperíodo de doze horas. Cada rolo possuía 15 sementes de cada um dos genótipos, em três repetições. Em seqüência, os rolos foram colocados numa cuba com água destilada. Após o décimo dia de germinação, as plântulas foram descartadas. O papel foi observado sob luz ultravioleta, para demarcação das áreas de fluorescência, e estas, identificadas pela coloração azul-fluorescente. Amostra autêntica de escopoletina (Sigma) foi usada como referência. Assim, as áreas com escopoletina foram demarcadas e, posteriormente, avaliadas em medidor de área foliar (Li-Cor modelo LI-3000).

\section{Testes biológicos com plântulas}

Foi montado um experimento de germinação com plântulas dos 20 genótipos de aveia, com 24 horas de cres- cimento. Foram colocadas cinco plântulas dispostas circularmente, junto com cinco sementes de trigo ou dez de azevém, cobertas com papel filtro no centro de cada placa de Petri. Foram adicionados $6 \mathrm{~mL}$ de solução nutritiva de Hoagland meia-força. As placas foram colocadas em câmara de crescimento a $18^{\circ} \mathrm{C}$ e fotoperíodo de doze horas, simulando-se condições de estação fria. $\mathrm{O}$ experimento prolongou-se por oito dias, empregando-se cinco repetições.

No experimento de crescimento foram usadas plântulas de aveia, trigo e azevém, com 24 horas de crescimento, dispostas em potes de plástico escuro de $200 \mathrm{~mL}$, preenchidos com vermiculita. Foram colocadas cinco plântulas de cada genótipo de aveia, em formato circular, com cinco plântulas de trigo e/ou azevém dispostas no centro do pote. Em cada pote foram colocados $70 \mathrm{~mL}$ de solução nutritiva meia-força. Depois de dez dias, as plântulas foram coletadas, e mediu-se o comprimento das raízes e da parte aérea. Em seguida, foram colocadas em estufa a $50^{\circ} \mathrm{C}$, e pesadas, para determinação da matéria seca. Foram usadas cinco repetições por tratamento.

\section{Análise cromatográfica dos exsudados}

Para análise cromatográfica das substâncias fluorescentes presentes nos exsudados das raízes dos genótipos de aveia, as sementes foram colocadas para germinar em rolos de papel, e, após dez dias de germinação as plântulas foram descartadas. O papel foi observado em luz ultravioleta, e foi marcada e recortada a área fluorescente e colocada em acetona, para extração do material. As amostras foram analisadas por cromatografia em camada delgada (CCD), em placas de sílica gel $60 \mathrm{~F}_{254}$ (Merck), tendo como sistema de solventes tolueno-clorofórmio-acetona $(40: 25: 35, \mathrm{v} / \mathrm{v} / \mathrm{v})$. Amostras autênticas (Sigma) de escopoletina, umbeliferona e escoparona foram diluídas em acetona e utilizadas como padrões. Após o desenvolvimento, a placa foi observada sob luz ultravioleta, sendo marcadas as substâncias e calculados os Rfs.

\section{Testes biológicos com escopoletina}

As concentrações de escopoletina foram estabelecidas em $10^{-4}$ e $10^{-5} \mathrm{M}$. Os experimentos de germinação foram realizados em placas de Petri, com papel filtro, colocandose em cada placa 20 sementes de trigo ou azevém e mantidas em câmara de crescimento a $18^{\circ} \mathrm{C}$, durante oito dias. Foram usadas cinco repetições por tratamento. Nos experimentos de crescimento, foram usadas cinco plântulas com 24 horas de crescimento por pote de plástico de $200 \mathrm{~mL}$, preenchido com vermiculita, acrescidos de $70 \mathrm{~mL}$ de solução nutritiva de Hoagland meia-força com 
escopoletina diluída. Os potes foram colocados em câmara de crescimento a $18^{\circ} \mathrm{C}$ e fotoperíodo de doze horas. Após dez dias, as plantas foram retiradas, e mediu-se o comprimento das raízes e da parte aérea. Depois foram colocadas em estufa a $50^{\circ} \mathrm{C}$ e pesadas, para determinação da matéria seca.

Nos experimentos foram usados os delineamentos completamente casualisados (DCC), e o fatorial. As médias dos tratamentos foram comparadas pelo teste de Duncan a $5 \%$.

\section{RESULTADOS E DISCUSSÃO}

\section{Avaliação da exsudação de escopoletina pelas raízes da aveia}

Vários trabalhos foram conduzidos nos últimos anos, na tentativa de avaliar o potencial alelopático das plantas cultivadas, em relação às espécies infestantes. Nesta linha, Fay \& Duke (1977) avaliaram o potencial alelopático de aveia quanto à exsudação radicular de escopoletina. Experimento semelhante foi feito neste trabalho, com triagem de 20 genótipos de aveia. Entretanto, diferentemente destes autores, esta área foi aqui avaliada em um medidor de área foliar. Também foi feita análise cromatográfica destas áreas, para comprovação da escopoletina. Essa técnica revelou que os genótipos que mais exsudaram escopoletina foram UFRGS 10, UPF 5, UFRGS 6, UPF 14, UPF 13, UFRGS 11 e UFRGS 9 (Fig. 1), os que menos a exsudaram foram UPF 15, UPF 12, UFRGS 12, UFRGS 7, aveiapreta, UPF 7 e UFRGS 17 (Fig. 1). A existência de genótipos de aveia que exsudam mais escopoletina que outros pode ser um indicativo para determinação do potencial alelopático destas plantas.

\section{Análise cromatográfica dos exsudados}

A parte azul-fluorescente encontrada nos papéis que estiveram em contato com as radículas dos genótipos de aveia foi considerada como sendo escopoletina. Como outras substâncias podem apresentar esta coloração na luz ultravioleta, estes papéis tiveram seu material extraído e colocado a desenvolver em sistema cromatográfico próprio para cumarinas. O material azul-fluorescente teve o mesmo comportamento cromatográfico da amostra autêntica de escopoletina (Sigma) (Fig. 2). Outras subs- tâncias apareceram nos exsudados, mas não foram identificadas.

\section{Testes biológicos com plântulas de aveia}

É possível que existam outros aleloquímicos presentes nos exsudados das radículas de plântulas de aveia. Por isso, além da triagem feita através da quantidade de escopoletina, realizaram-se testes com plântulas de aveia, para se obter uma avaliação mais ampla do potencial alelopático desses genótipos. Nos testes biológicos sobre a germinação de azevém (Fig. 3A), pode-se observar que o maior efeito inibidor foi provocado pelos genótipos UFRGS 10, UFRGS 6, UPF 13, UFRGS 11, UFRGS 9 e UFRGS 4. Quanto ao crescimento, quase todos inibiram o crescimento da radícula de azevém, e os mais ativos foram UFRGS 9

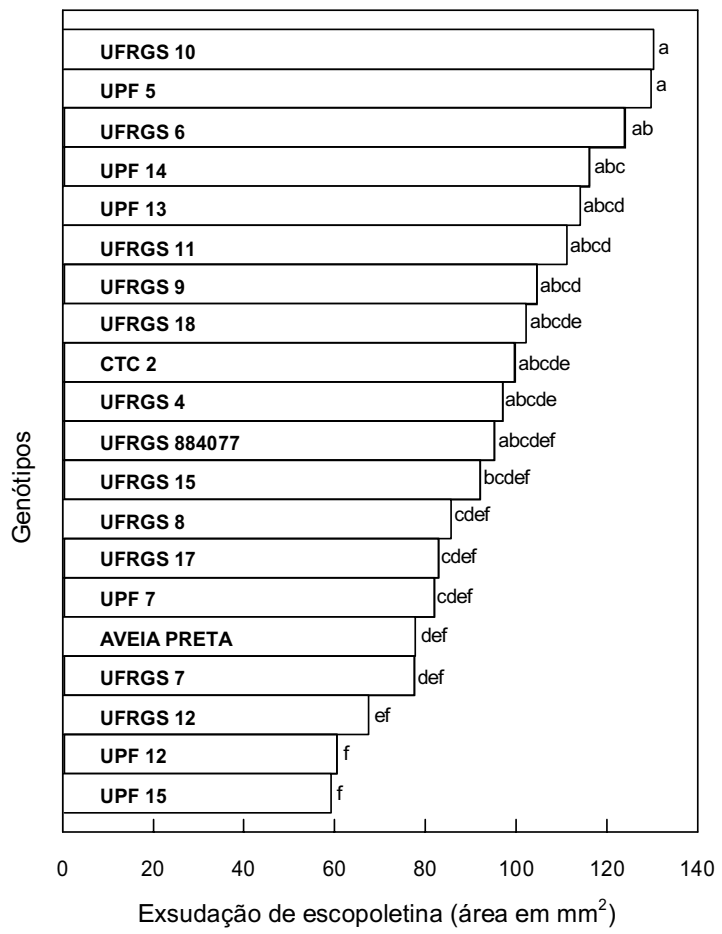

FIG. 1. Exsudação de escopoletina pelas radículas de plântulas de genótipos de aveia, avaliadas até o $10^{\circ}$ dia de desenvolvimento em papel germinador. Tratamentos seguidos de letras distintas diferem entre si $(\alpha=0,05$; teste de Duncan). 
e UFRGS 6 (Fig. 3B). Na parte aérea (Fig. 3C), os mais ativos foram UFRGS 10 e UPF 5. Quanto à matéria seca, apenas o genótipo UFRGS 12 não inibiu o crescimento, enquanto os de maior efeito foram UFRGS 9, UPF 13, UFRGS 10 e UPF 14 (Fig. 3D).

Quanto à germinação do trigo, apenas os genótipos UFRGS 6, UFRGS 9, UFRGS 10 e UPF 13 promoveram inibição (Fig. 4). Entretanto, todos inibiram o crescimento radicular de trigo (comprimento), destacando-se principalmente UPF 13, UFRGS 9, UFRGS 6, CTC 2 e UFRGS 10 (Fig. 5A). O mesmo foi observado em termos de matéria seca (Fig. 5B). Na parte aérea (Fig. 5C e 5D), todos inibiram tanto o comprimento quanto a matéria seca de trigo, sendo os mais eficazes UPF 13, UFRGS 10, UFRGS 6 e UFRGS 9.

Numa avaliação geral das variáveis, os genótipos que demonstraram maior efeito inibitório incluemse entre os que mais exsudaram escopoletina, como UPF 13, UFRGS 9, UFRGS 10 e UFRGS 6; os

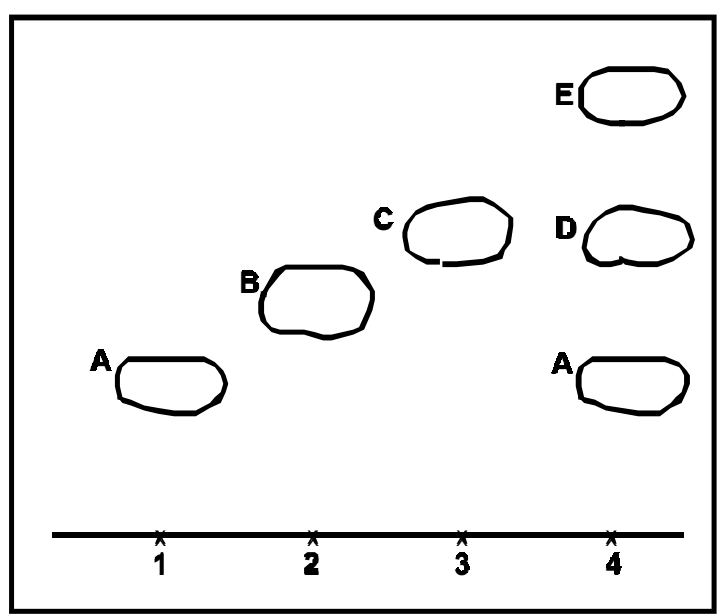

FIG. 2. Representação esquemática do cromatograma de exsudados de radículas de plântulas de aveia e soluções de derivados cumáricos (Sigma) eluídas na mistura de solventes tolueno-clorofórmio-acetona $(40: 25: 35, \mathrm{v} / \mathrm{v} / \mathrm{v})$, adsorvente sílica gel e detecção sob luz ultravioleta. Amostras autênticas: 1. Escopoletina; 2. Umbeliferona; 3. Escoparona; 4. Exsudado radicular: A. Escopoletina; D e E. Compostos não identificados. genótipos que apresentaram menor efeito relacionamse entre os que menos exsudaram o composto, como UFRGS 12, UFRGS 17, UFRGS 884077 e UPF 12 (Figs. $1,3,4$ e 5 ).

Conseqüentemente, fica claro que existe uma relação entre a quantidade de escopoletina exsudada e o potencial alelopático destes genótipos de aveia. Outro fato que corrobora esta constatação foi o pronunciado efeito inibidor dos genótipos sobre as radículas de trigo e de azevém, o que comprova indicações da literatura de que a escopoletina é um eficiente inibidor do crescimento radicular (Goodwin \& Taves, 1950; Pollock et al., 1954; Avers \& Goodwin, 1956). Estes resultados permitem embasar o desenvolvimento e aproveitamento de cultivares de aveia pela aptidão em inibir as infestantes desta cultura.

\section{Testes biológicos com escopoletina}

Nos experimentos com escopoletina, buscou-se analisar seus efeitos, bem como sua relação com a alelopatia demonstrada pelos genótipos de aveia, e ainda estimar sua concentração. Com base nos trabalhos de Goodwin \& Kavanagh (1949) e Goodwin \& Pollock (1954), as concentrações de escopoletina usadas neste experimento foram $10^{-5}$ e $10^{-4} \mathrm{M}$. A menor concentração foi estabelecida na tentativa de aproximar seu valor do que é exsudado pelas raízes, e a maior com o que é encontrado nas raízes de aveia.

A escopoletina inibiu a germinação de azevém (Tabela 1), mas não houve diferença significativa entre as concentrações utilizadas. Por outro lado, no que se refere ao trigo, não foi verificada inibição (Tabela 2). No crescimento do azevém, a escopoletina inibiu o crescimento da raiz e da parte aérea e a produção de matéria seca (Tabela 1$)$. O crescimento das raízes do trigo (comprimento) também foi inibido pela escopoletina (Tabela 2). Em termos de matéria seca, apenas a concentração mais alta $\left(10^{-4} \mathrm{M}\right)$ ocasionou inibição. No crescimento da parte aérea, houve inibição (Tabela 2), mas em termos de matéria seca, não se detectou variação.

Estes resultados permitem inferir que o uso de escopoletina pode controlar plantas infestantes, pois apresentam maior fitotoxicidade para o azevém e menor para o trigo. 

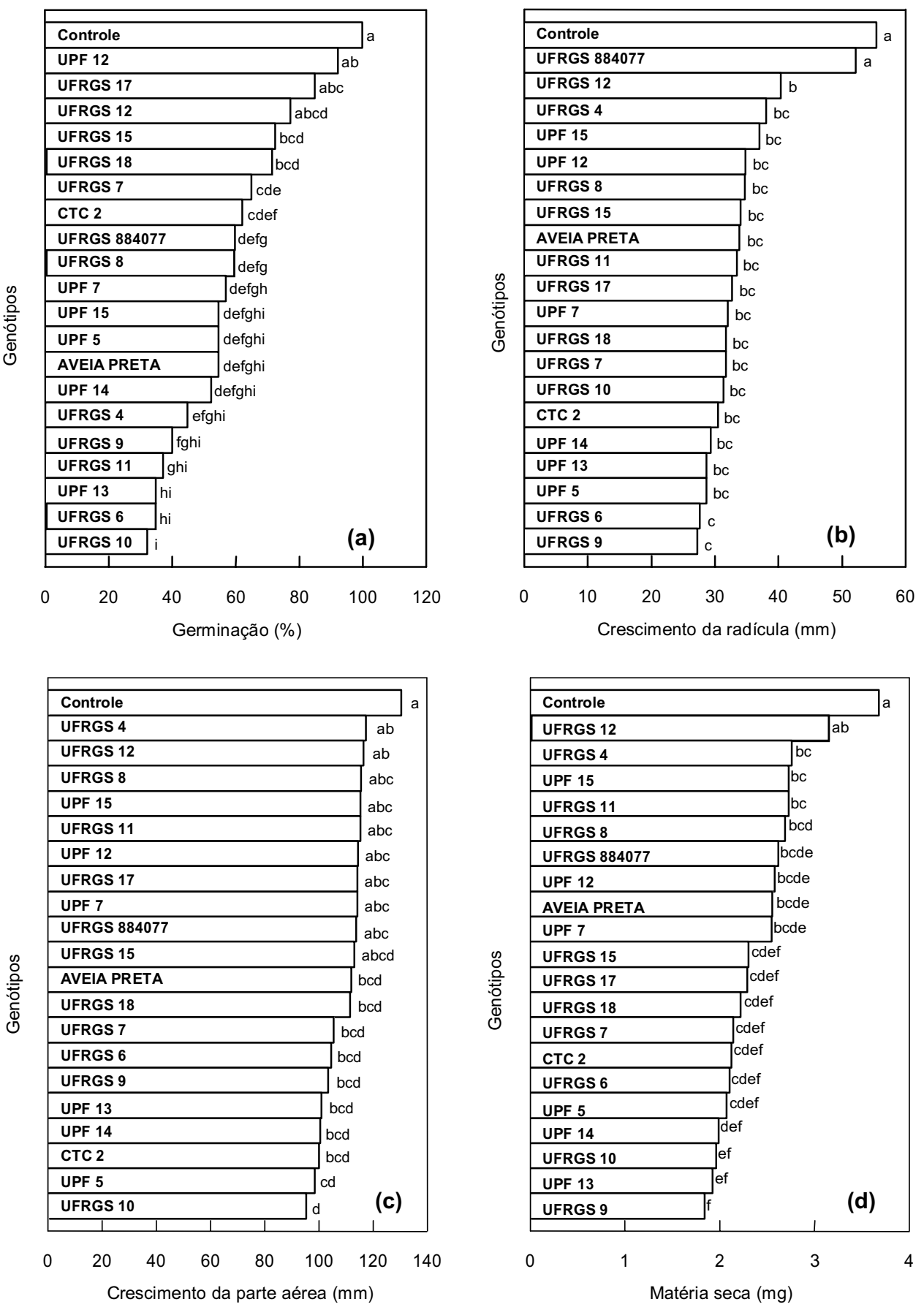

FIG. 3. Efeito da exsudação radicular de genótipos de aveia sobre germinação (a), crescimento da radícula (b), crescimento da parte aérea (c) e matéria seca (d) de plântulas de azevém (Lolium multiflorum). A germinação do controle é considerada $100 \%$. Tratamentos seguidos de letras distintas diferem entre si $(\alpha=0,05$; teste de Duncan). 


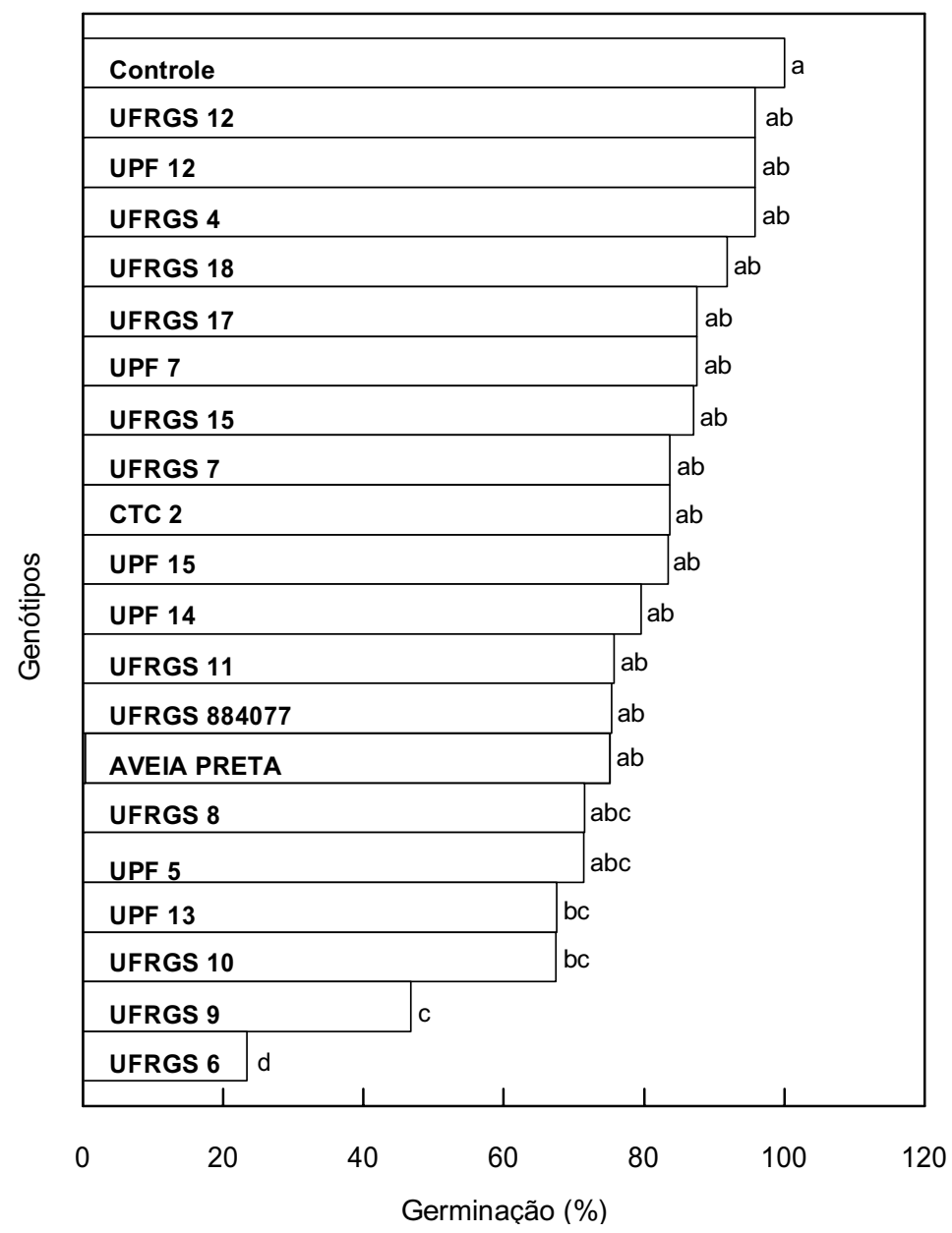

FIG. 4. Efeito da exsudação radicular de genótipos de aveia sobre a germinação de sementes de trigo (Triticum aestivum). A germinação do controle é considerada $100 \%$. Tratamentos seguidos de letras distintas diferem entre si $(\alpha=0,05$; teste de Duncan).

Em termos gerais, pode-se verificar que os efeitos produzidos pela escopoletina foram equivalentes aos provocados pelos genótipos de aveia. Este fato mostra uma relação entre ambos, o que indica o efeito alelopático relacionado à escopoletina e sua concentração. Entretanto, a estimativa da concentração através de seus efeitos não se mostrou evidente, pois só em alguns casos foi possível estabelecer associação. Também são encontrados cumarina, ácido p-hidroxibenzóico e ácido vanílico em exsudados radiculares de Avena fatua (Perez \& Nunez, 1991), e podem ocorrer outros aleloquímicos nos exsudados dos genótipos, os quais, combinados à ação da escopoletina, podem potencializar os efeitos alelopáticos encontrados.

Devido à grande variabilidade quanto ao potencial alelopático observado nos genótipos de aveia neste trabalho, é possível sugerir o seu aproveitamento direto ou o desenvolvimento de novas cultivares mais aptas a concorrer com infestantes desta cultura. 

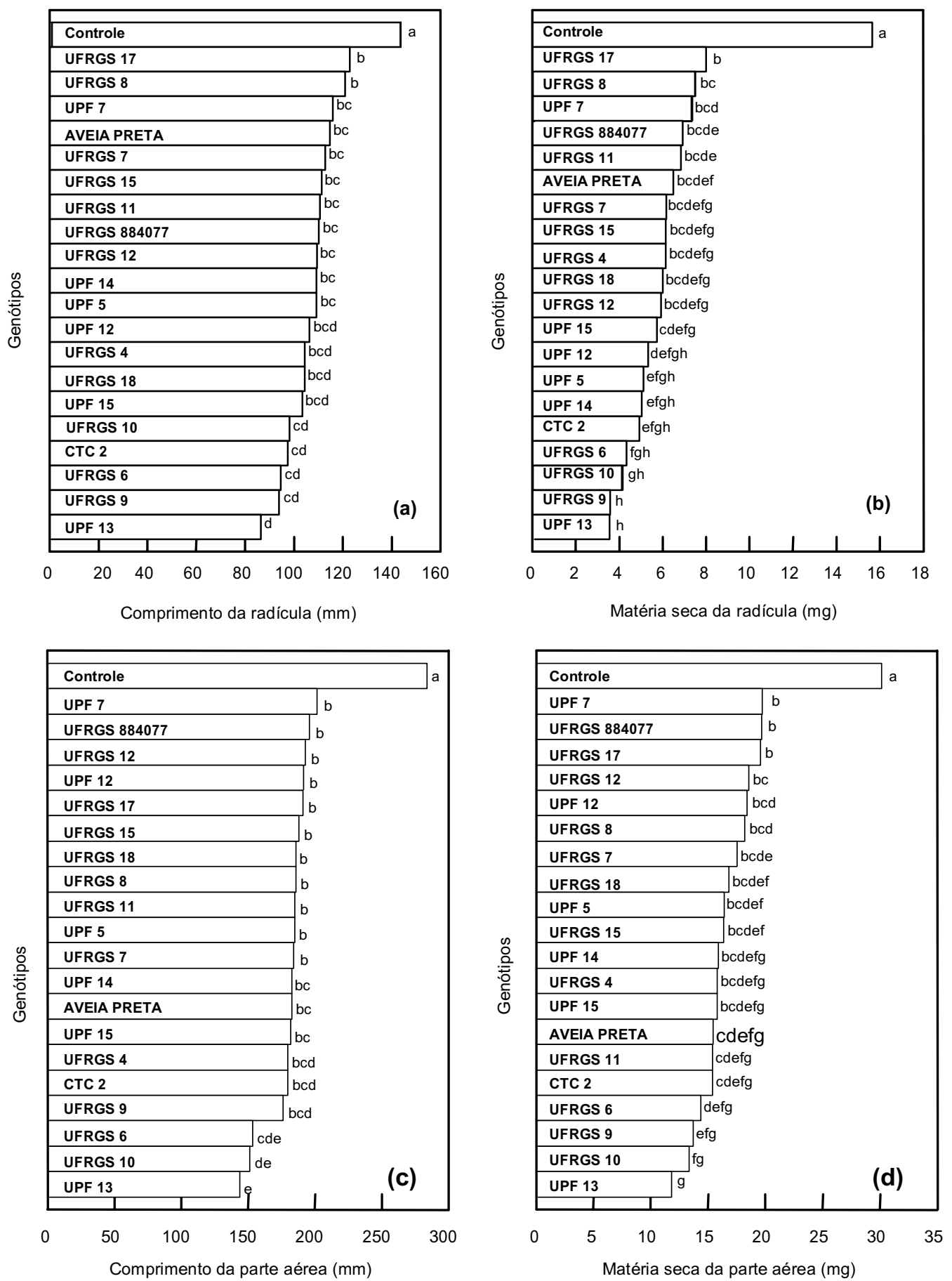

FIG.5. Efeito da exsudação radicular de genótipos de aveia sobre o crescimento (a) e matéria seca da radícula (b), crescimento (c) e matéria seca da parte aérea (d) de plântulas de trigo (Triticum aestivum). Tratamentos seguidos de letras distintas diferem entre si $(\alpha=0,05$; teste de Duncan). 
TABELA 1. Efeito da escopoletina sobre a germinação e o crescimento de azevém (Lolium multiflorum) ${ }^{1}$.

\begin{tabular}{lccc}
\hline Parâmetros & \multicolumn{3}{c}{ Concentrações de escopoletina } \\
\cline { 2 - 4 } & Controle $^{2}$ & $10^{-5} \mathrm{M}$ & $10^{-4} \mathrm{M}$ \\
\hline Germinação (\%) & $100 \mathrm{a}$ & $89 \mathrm{~b}$ & $86 \mathrm{~b}$ \\
Comprimento da radícula (mm) & $41 \mathrm{a}$ & $29 \mathrm{~b}$ & $20 \mathrm{c}$ \\
Comprimento da parte aérea (mm) & $146 \mathrm{a}$ & $119 \mathrm{~b}$ & $109 \mathrm{c}$ \\
Matéria seca da plântula (mg) & $2,6 \mathrm{a}$ & $1,9 \mathrm{~b}$ & $2,0 \mathrm{~b}$ \\
\hline
\end{tabular}

${ }^{1}$ Valores seguidos de letras distintas, comparados nas linhas, diferem entre si $(\alpha=0,05$; teste de Duncan).

${ }^{2}$ A germinação do controle é considerada $100 \%$.

TABELA 2. Efeito da escopoletina sobre a germinação e o crescimento de trigo (Triticum aestivum) ${ }^{1}$.

\begin{tabular}{lccc}
\hline Parâmetros & \multicolumn{3}{c}{ Concentrações de escopoletina } \\
\cline { 2 - 4 } & Controle $^{2}$ & $10^{-5} \mathrm{M}$ & $10^{-4} \mathrm{M}$ \\
\hline Germinação (\%) & $100 \mathrm{a}$ & $92 \mathrm{a}$ & $93 \mathrm{a}$ \\
Comprimento da radícula (mm) & $118 \mathrm{a}$ & $87 \mathrm{~b}$ & $84 \mathrm{~b}$ \\
Matéria seca da radícula (mg) & $6,5 \mathrm{a}$ & $5,8 \mathrm{ab}$ & $5,6 \mathrm{~b}$ \\
Comprimento da parte aérea (mm) & $226 \mathrm{a}$ & $203 \mathrm{~b}$ & $187 \mathrm{~b}$ \\
Matéria seca da parte aérea (mg) & $19 \mathrm{a}$ & $18 \mathrm{a}$ & $16 \mathrm{a}$ \\
\hline
\end{tabular}

${ }^{1}$ Valores seguidos de letras distintas, comparados nas linhas, diferem entre si $(\alpha=0,05$; teste de Duncan).

${ }^{2}$ A germinação do controle é considerada $100 \%$.

\section{CONCLUSÕES}

1. Os genótipos de aveia que mostram maior efeito alelopático estão entre os que mais exsudam escopoletina pelas raízes, e os que apresentam menor efeito incluem-se entre os de menor exsudação.

2. Os genótipos de aveia que apresentam maior potencial alelopático são UPF 13, UFRGS 9, UFRGS 10 e UFRGS 6, e os de menor potencial são UFRGS 12, UFRGS 17, UFRGS 884077 e UPF 12.

3. Os efeitos produzidos pelo aleloquímico escopoletina são similares aos provocados pelos genótipos, o que sugere relação entre o efeito alelopático da substância e dos genótipos.

4. As ações alelopáticas provocadas pela escopoletina mostram maior fitotoxicidade na planta invasora (azevém) do que na cultivada (trigo).

\section{REFERENCIAS}

ALSAADAWI, I.S. Biological suppression of nitrification by selected cultivars of Helianthus annuus L. Journal of Chemical Ecology, New York, v.14, n.3, p.722$742,1988$.

AVERS, C.J.; GOODWIN, R.H. Studies on roots. IV. Effects of coumarin and scopoletin on the standard root growth pattern of Phleum pratense. American Journal of Botany, Baltimore, v.43, p.612-620, 1956.

DILDAY, R.H.; FRANS, R.E.; SEMIDEY, N.; SMITH, R.J.; OLIVER, L.R. Weed control with crop allelopathy. Arkansas Farm Research, Fayetteville, v.41, n.4, p.14-15, 1992.

FAY, P.K.; DUKE, W.B. An assessment of allelopathic potential in Avena germ plasm. Weed Science, Champaign, v.5, n.3, p.224-228, 1977. 
GOODWIN, R.H.; KAVANAGH, F. The isolation of scopoletin, a blue-fluorescing compound from oat roots. Bulletin of the Torrey Botanical Club, New York, v.76, n.4, p.255-265, 1949.

GOODWIN, R.H.; POLLOCK, B.M. Studies on roots. I. Properties and distribution of fluorescent constituents in Avena roots. American Journal of Botany, Baltimore, v.41, p.516-520, 1954.

GOODWIN, R.H.; TAVES, C. The effect of coumarin derivatives on the growth of Avena roots. American Journal of Botany, Baltimore, v.37, p.324-331, 1950.

JACOBI, U.S. Avaliação do potencial alelopático de Avena sp. (L.). Porto Alegre: UFRGS, Faculdade de Agronomia, 1997. 165p. Tese de Doutorado.

JAMES, K.L.; BANKS, P.A.; KARNOK, K.J. Interference of soybean, Glycine max, cultivars with sicklepod, Cassia obtusifolia. Weed Technology, v.2, p.404409,1988
LEATHER, G.R. Sunflowers (Helianthus annuus) are allelopathic to weeds. Weed Science, Champaign, v.31, n.1, p.37-42, 1983.

PEREZ, F.J.; NUNEZ, J.O. Root exudates of wild oats. Allelopathic effect on spring wheat. Phytochemistry, Oxford, v.30, n.7, p.2199-2202, 1991.

POLLOCK, B.M.; GOODWIN, R.H.; GREENE, S. Studies on roots. II. Effects of coumarin, scopoletin and other substances on growth. American Journal of Botany, Baltimore, v.41, p.521-529, 1954.

PUTNAM, A.R.; DUKE, W.B. Biological suppression of weeds: evidence for allelopathy in accessions of cucumber. Science, Washington, v.185, n.4148, p.370-372, 1974.

ROSE, S.J.; BURNSIDE, O.C.; SPECHT, J.E.; SWISHER, B.A. Competition and allelopathy between soybeans and weeds. Agronomy Journal, Madison, v.76, n.4, p.523-528, 1984. 